\title{
REVISÃO SISTEMÁTICA SOBRE EDUCAÇÃO INCLUSIVA DE SURDOS NO ENSINO DA MATEMÁTICA
}

\section{SYSTEMATIC REVIEW ON INCLUSIVE EDUCATION OF DEAF IN MATHEMATICS TEACHING}

DOI: http://dx.doi.org/10.5965/1984317815032019086

\author{
Cíntia Moralles Camillo \\ Universidade Federal de Santa Maria \\ cintiacamillo@gmail.com \\ Liziany Muller Medeiros \\ Universidade Federal de Santa Maria \\ lizianyn@hotmail.com
}

\begin{abstract}
RESUMO
O presente artigo objetivou analisar os sinais em Libras como possibilidade no ensino da matemática, relacionando as dificuldades dos educandos surdos com a linguagem matemática e com o raciocínio lógico, para tanto realizou-se uma revisão sistemática de literatura, no período de 2010 a 2017. Para a obtenção dos artigos, teses e dissertações a serem analisados, utilizaram-se os descritores "libras e matemática", "educação especial e matemática", "inclusão e matemática", "surdos e matemática" na base de dados Scielo (Scientific Eletronic Library Online) e na Biblioteca Digital Brasileira de Teses e Dissertações (BDTD). Primeiramente foram lidos os resumos dos artigos encontrados e assim selecionadas as pesquisas a serem utilizadas na análise. Os critérios de inclusão de artigos foram aqueles publicados em periódicos nacionais e que analisavam o assunto proposto, conforme o objetivo do artigo. Em todos os estudos foram relatados que os estudantes surdos conheciam a língua dos sinais, mais não conheciam nenhum símbolo matemático, expressão, figura geométrica e a construção de números, consequentemente apresentaram dificuldades e deficit no raciocínio lógico.
\end{abstract}

Palavras-chave: Libras. Educação Matemática. Educandos Surdos. Identidade Surda. Revisão Sistemática.

\begin{abstract}
The present article aimed to analyze the signs in Libras as a possibility in the teaching of mathematics, relating the difficulties of deaf students with mathematical language and logical reasoning. A systematic review of the literature was carried out between 2010 and 2017. In order to obtain the articles, theses and dissertations to be analyzed, the descriptors "pounds and mathematics", "special education and mathematics", "inclusion and mathematics", "deaf and mathematical" were used in the Scielo database Library Online) and the Brazilian Digital Library of Theses and Dissertations (BDTD). First the summaries of the articles were read and thus the researches to be used in the analysis were selected. The criteria for inclusion of articles were those published in national journals and that analyzed the proposed subject, according to the purpose of the article. In all studies it was reported that deaf students knew the language of the signs, but they did not know any mathematical symbol, expression, geometric figure and the construction of numbers, consequently presented difficulties and deficits in the logical reasoning.
\end{abstract}

Keywords: Libras. Mathematical Education. Deaf students. Identity Deaf. Systematic review. 


\title{
1 INTRODUÇÃO
}

Atualmente a educação tem passado por grandes transformações, principalmente em relação à educação especial e à inclusão. O contexto escolar é composto por diversidades, muitos são os desafios, principalmente para o educador que tem que lidar com a heterogeneidade e promover o ensino e a aprendizagem aos educandos de forma justa e respeitando as diferenças.

Segundo Souza et al. (2014), é importante notar que a educação para os educandos surdos é relatada pela legislação, que assegura uma educação que contemple os surdos em virtude da necessidade da língua. Sabe-se que a comunidade surda desde muito tempo vem lutando pela igualdade e respeito de sua cultura, especialmente aos diretos no campo linguísticos educacional, econômico e social.

Desta forma, a Língua Brasileira de Sinais (Libras) foi regulamentada:

\begin{abstract}
Pela Lei 10.436 e oficializada em 24 de abril de 2002, relata em seu Art. $1^{\circ}$ como sendo reconhecida como meio legal de comunicação e expressão em que o sistema linguístico de natureza visual-motora, contendo estrutura gramatical própria, constitui um sistema linguístico de transmissão de ideias e fatos, oriundos de comunidades de pessoas surdas do Brasil (BRASIL, $2002, \mathrm{~s} / \mathrm{p})$.
\end{abstract}

Por conseguinte, a Lei 10.436 leva a reconhecer a importância da Libras no âmbito escolar, profissional e da sociedade em geral. Porém, o histórico da educação dos surdos nos mostra que as atenções se voltaram para a aprendizagem da língua portuguesa. Pertinente ao exposto, pensa-se: como os educadores estão trabalhando a matemática na sala de aula com os educandos surdos? Os educandos surdos apresentam dificuldades significativas em aprender matemática?

Neste contexto, o presente artigo objetivou realizar uma revisão sistemática de literatura, no período de 2010 a 2017, que analisaram os sinais em Libras como possibilidade de ensino da matemática, relacionando as dificul- 
dades dos educandos surdos com a linguagem matemática e com o raciocínio lógico.

Ao decorrer do artigo versa-se sobre o perfil e diferenças de um povo, bem como a sua identidade surda. Abordar-se sobre a educação dos surdos, Educação Matemática e posteriormente, é apresentado a metodologia, os resultados e discussões da revisão sistemática dos artigos selecionados abarcando sobre as possibilidades do ensino da matemática e as dificuldades dos educandos surdos com a linguagem matemática; e para finalizar as considerações finais.

\section{Perfil e diferenças de um povo: Identidade surda}

Os povos surdos por meio de movimentos sociais e pela união em favor de uma causa maior, vêm contribuindo para que haja um novo olhar no processo histórico, cultural e educacional. Para Souza et al. (2014), com as mudanças ocorridas ao longo do tempo em nossa sociedade, principalmente no que se refere a aceitação do sujeito surdo, a educação vem possibilitando a inserção destes no processo educativo, os autores ainda frisam que este processo ainda não alcançou sua plenitude e que ainda existem várias barreiras a serem vencidas.

Arroyo (2014) em sua obra intitulada de Outros Sujeitos, Outras Pedagogias, retrata muito bem a respeito do reconhecimento destes "Outros Sujeitos", outros educandos, que necessitam lutar por meio de movimentos sociais para que tenham o seu direito assegurado. Contudo, o autor faz várias perguntas que merecem ser refletidas, uma delas se encaixa perfeitamente no estudo em questão, como: Por que a história da pedagogia ignorou estes sujeitos e outras pedagogias para estes sujeitos?

Refletindo sobre a pergunta, porque não existe uma forma concreta de ensinar matemática para esses sujeitos surdos?

É por meio da cultura que uma comunidade se constitui, integra e identifica os sujeitos. Ou seja, a existência de uma cultura fortalece a identidade de 
um povo. Para Pereira (2011), assim como qualquer outra cultura, os membros das comunidades surdas compartilham valores, crenças, comportamentos e o mais importante, uma língua diferente.

Ao lidar-se com os educandos surdos deve-se levar em consideração suas "potencialidades, o nível de surdez, o fato de ser pré-linguística ou póslinguística, entre outros fatores" (LIMA e CONCEIÇÃO, 2015, p.04).

Assim, conforme Miranda e Miranda (2011, p.32) os surdos são divididos em dois grupos:

No primeiro grupo, são os que possuem surdez profunda desde seu nascimento, ou seja, nunca ouviram som algum. No segundo grupo, são os que apresentam surdez moderada e leve e também os ensurdecidos, ou seja, seriam aqueles que com uma prótese auditiva conseguem captar os sons da fala e normalmente conseguem atingir certo nível de oralização.

Ainda segundo os autores "dentro desse segundo grupo encontramos também os ensurdecidos pós-linguísticos, que ficaram surdos após terem sua língua oral constituída" (MIRANDA e MIRANDA, 2011, p.33).

Em conformidade com Lima e Conceição (2015, p.06), em relação a identidade surda:

O grau de perda auditiva e do comprometimento linguístico, a época em que ocorreu a surdez determinará as características e a identidade de cada indivíduo. Quando falamos em identidade, estamos nos referindo a um termo muito comum encontrado em pesquisas no Brasil que tratam do aspecto cultural da surdez. Este termo aparece nos textos como "identidade surda".

Em construção ou frequentemente sendo transformada, a identidade de um sujeito pode estar em constante movimento, assim, para Skliar (2011), a identidade surda possui múltiplas e diferentes categorias, definidas no Quadro 1.

Quadro 1 - A surdez: um olhar sobre as diferenças

\begin{tabular}{|c|c|}
\hline $\begin{array}{c}\text { Categoria } \\
\mathbf{s}\end{array}$ & Definição \\
\hline
\end{tabular}




\begin{tabular}{|l|l|}
\hline Flutuante & $\begin{array}{l}\text { Estão presentes onde os surdos vivem, e se manifestam a partir da hegemonia dos } \\
\text { ouvintes. }\end{array}$ \\
\hline Incompleta & $\begin{array}{l}\text { Surdos que vivem uma ideologia ouvintista, na tentativa de uma reprodução da identidade } \\
\text { dominante (ouvinte). }\end{array}$ \\
\hline Transição & $\begin{array}{l}\text { A passagem do mundo ouvinte, com representação da identidade ouvinte para a } \\
\text { identidade surda no contexto mais visual. }\end{array}$ \\
\hline Híbrida & $\begin{array}{l}\text { São surdos que nasceram ouvintes e com o tempo se tornaram surdos. Estes terão } \\
\text { presentes às duas línguas numa dependência dos sinais e do pensamento na língua oral. }\end{array}$ \\
\hline Surda & $\begin{array}{l}\text { Fazem uso da experiência visual dentro de um espaço cultural diverso. A identidade } \\
\text { política surda. }\end{array}$ \\
\hline
\end{tabular}

Fonte: Adaptado de Skliar (2011)

Portanto, entende-se que todos os surdos possuem entre outras como vimos acima, uma identidade surda, porém, está se apresenta de formas variadas e/ou conforme as representações. A seguir, aborda-se brevemente a educação dos surdos no Brasil.

\section{Educação de surdos}

No contexto escolar da atualidade, observa-se que muitos educadores tendem a tratar o seu educando de forma igualitária, mesmo vivendo em um mundo que hoje se prega as aprendizagens múltiplas e variadas, em que o educador tem que se moldar aos valores pessoais e culturais dos educandos.

Eis que alguns educadores, não a maioria, acredita que ter o domínio dos conceitos e conteúdos de suas disciplinas já é o bastante para ser um bom educador. Porém, para lidar com educandos surdos requer mais cuidados, não é simplesmente adaptar ou acrescentar a língua dos sinais em suas aulas.

Miranda e Miranda (2011, p.04) nos diz que "para ensinar, tanto alunos ouvintes quanto surdos, é preciso conhecer o estudante como um todo, desde sua vida até seus interesses para que ocorra a troca de conhecimento necessária para sua formação." Os autores ainda chamam a atenção de que sujeitos ouvintes devem se colocar no lugar do sujeito surdo, porque estes captam e tem sensações diferentes dos sujeitos ouvintes, logo, deve-se ter uma maior sensibilidade em lidar com estes indivíduos. 
Aprender vai muito além das experiências imediatas, exige que os sujeitos se apropriem de seus conhecimentos existentes e de suas vivências. A surdez é uma experiência visual em que "todos os mecanismos da informação se compreendem através do universo em torno do que se constroem por experiência visual" (SKLIAR, 2011, p.07).

Quadros (2005, p.08) defini a língua dos sinais como:

São línguas que são utilizadas pelas comunidades surdas. As línguas de sinais apresentam as propriedades específicas das línguas naturais, sendo, portanto, reconhecidas enquanto línguas pela Linguística. As línguas de sinais são visuais-espaciais captando as experiências visuais das pessoas surdas.

Nesse sentido, segundo os autores, deve-se discutir criticamente a questão das diferentes abordagens didáticas dentro do contexto escolar relacionado ao ensino e aprendizagem do educando surdo. Para Skliar (2011) a maior dificuldade para os surdos é encontrar profissionais da educação que estejam preparados para recebê-los em sala de aula e ainda capaz de rever continuamente suas práticas metodológicas.

A seguir, debruça-se brevemente sobre a Educação Matemática, abordando-se alguns pareceres sobre a linguagem matemática, a sua importância, bem como as dificuldades de os educandos com os termos matemáticos.

\section{Educação Matemática}

Ensinar matemática tem sido um desafio constante e é comum identificarmos que a matemática causa antipatia, hostilidade e até repulsa por parte dos educandos, os quais muitas vezes não entendem o sentido de estudar matemática. Por sua vez, encontra-se muitas vezes educadores desmotivados com o ato de ensinar matemática.

Observa-se, por meio de avaliações oficiais e pelos indicadores de eficácia da educação básica, que os educandos não estão alcançando um bom desenvolvimento no ensino e na aprendizagem. Fato mais evidente nas 
primeiras séries do Ensino Fundamental, fase está, muito importante para o sucesso do educando na escola (BRASIL, 2012).

O censo realizado pelo Instituto Nacional de Estudos e Pesquisas Educacionais (Inep, 2015), que tem como participantes escolas públicas brasileiras como as: particulares, urbanas e rurais, com educandos matriculados do $5^{\circ}$ ou $9^{\circ}$ anos do Ensino Fundamental e do Ensino Médio, estes indicam que nos últimos três censos realizados em 2005, 2010 e 2015 apenas 7,3\% dos educandos atingiram níveis satisfatórios e adequado em matemática. Porém, o índice é menor ainda quando considerado apenas as escolas públicas que possuem apenas $3,6 \%$ de educandos com o aprendizado adequado, significando que 96,4\% dos educandos não aprendem o esperado na escola (INEP, 2015).

A matemática é o alicerce para a sustentação de diversas áreas do conhecimento. Ela lida muitas vezes com conceitos abstratos e possui uma estrutura própria e autônoma, mesclando palavras e símbolos, pela simbiose entre linguagem matemática e linguagem natural (MACHADO, 2011). Com a multiplicidade de sentidos da sua linguagem, pode contribuir para o equívoco em seus enunciados matemáticos.

Cabe ao educador "situar a função da matemática no contexto de apropriação dos processos de escrita, leitura e pensar a comunicação em sala de aula desta disciplina" (COSTA e BARATA, 2016, p.10). Melhorando a distância entre o educando e a Educação Matemática, a fim de quebrar barreiras pré-existentes.

Neste contexto, a linguagem matemática é tida como obstáculo à aprendizagem da disciplina (MIRANDA, 2007). Se tornando por vezes, obstáculo em todo o sistema de ensino, se estendendo desde os anos iniciais da escolarização até o Ensino Médio, tornando-se constantemente um grande bloqueio na aprendizagem.

A matemática exige que o educador estimule o seu educando a construir o processo de aprendizagem. Muitas vezes, é necessário que este educando volte regularmente sobre os mesmos conteúdos já estudados, mas de forma 
diferenciada, exigindo que o este tenha uma alfabetização matemática apropriada para a interpretação matemática necessária.

Segundo Costa e Barata (2016) "é necessário buscar soluções para a superação das barreiras existentes para a concretização de um processo de ensino e aprendizagem em matemática". Assim, essas barreiras tendem a ser minimizadas quando o educador está disposto a ter uma melhor comunicação com o seu educando no contexto escolar, buscando proporcionar ao educando um melhor sentido a linguagem matemática.

\section{METODOLOGIA}

A revisão sistemática da literatura (RSL) é um método empírico que tem por objetivo identificar, avaliar e interpretar questões de pesquisa, área de um tópico, ou fenômeno em uma pesquisa. Segundo Kitchenham e Charters (2007), sua principal motivação é reunir provas para a fundamentação de conclusões, com as diretrizes necessárias para a realização de uma RSL. De acordo com estas orientações, o presente estudo é dividido em três principais fases: planejamento, realização e relatório.

Para a obtenção dos artigos, teses e dissertações a serem analisados, utilizaram-se os descritores "Libras e matemática", "educação especial e matemática", "inclusão e matemática", "surdos e matemática" na base de dados Scielo (Scientific Eletronic Library Online) e na Biblioteca Digital Brasileira de Teses e Dissertações (BDTD). O período de pesquisa incluiu estudos publicados entre 2010 e 2017.

Primeiramente, foram lidos os resumos dos artigos encontrados e assim selecionadas as pesquisas a serem utilizadas na análise. Os critérios de inclusão de artigos foram aqueles publicados em periódicos nacionais e que analisavam os sinais em Libras como possibilidade de ensino de matemática, dificuldade dos educandos surdos com a linguagem matemática e o raciocínio matemático. 


\section{RESULTADOS E DISCUSSÕES}

Este tópico apresenta os principais resultados dos estudos. Foram encontrados no total de vinte e cinco artigos, utilizando os descritores na base de dados Scielo dos quais cinco se encaixaram nos critérios de inclusão e foram selecionados para a análise; na BDTD foram selecionados duas dissertações de mestrado e uma tese de doutorado. No Quadro 1 são apresentados os estudos selecionados para a RSL do período de 2010 a 2017, apresentando a autor do estudo, ano de publicação, local da pesquisa, publicação no portal Scielo ou na BDTD e o título do estudo.

\begin{tabular}{|c|c|c|c|c|}
\hline Autor & Ano & Local da Pesquisa & $\begin{array}{l}\text { Periódico do } \\
\text { Portal Scielo ou } \\
\text { BDTD }\end{array}$ & Título \\
\hline $\begin{array}{l}\text { A r n o I d o } \\
\text { Junior et al. }\end{array}$ & 2013 & $\begin{array}{l}\text { Porto Alegre/RS - } \\
\text { Escola de Surdos }\end{array}$ & $\begin{array}{c}\text { Cadernos CEDES/ } \\
\text { Scielo }\end{array}$ & $\begin{array}{l}\text { O uso do multiplano por alunos } \\
\text { surdos e o desenvolvimento do } \\
\text { pensamento geométrico }\end{array}$ \\
\hline Barbosa & 2014 & $\begin{array}{l}\text { São Paulo/SP - } \\
\text { Centro Infantil Público } \\
\text { e Centro Infantil } \\
\text { Privado }\end{array}$ & $\begin{array}{c}\text { Educação e } \\
\text { Pesquisa/Scielo }\end{array}$ & $\begin{array}{l}\text { Conceitos matemáticos iniciais e } \\
\text { l i n g u a g e } \mathrm{m} \text { : u m e s t u d o } \\
\text { comparativo entre crianças surdas } \\
\text { e ouvintes }\end{array}$ \\
\hline $\begin{array}{l}\text { Corrê a e } \\
\text { Kopke }\end{array}$ & 2013 & $\begin{array}{l}\text { Rio de Janeiro/RJ - } \\
\text { Instituto Nacional de } \\
\text { Educação de Surdos }\end{array}$ & $\begin{array}{c}\text { Tese (doutorado)/ } \\
\text { BDTD }\end{array}$ & $\begin{array}{l}\text { A divisão por alunos surdos: } \\
\text { ideias, representações e } \\
\text { ferramentas matemáticas }\end{array}$ \\
\hline $\begin{array}{l}\text { Fernandes e } \\
\text { Healy }\end{array}$ & 2016 & $\begin{array}{l}\text { Barueri/São Paulo - } \\
\text { Escola Pública } \\
\text { Municipal }\end{array}$ & $\begin{array}{c}\text { Ciência e } \\
\text { Educação/Scielo }\end{array}$ & $\begin{array}{l}\text { A emergência do pensamento } \\
\text { algébrico nas atividades de } \\
\text { aprendizes surdos }\end{array}$ \\
\hline $\begin{array}{l}\text { Fernández- } \\
\text { Viader e } \\
\text { Fuentes }\end{array}$ & 2013 & Barcelona/Espanha & $\begin{array}{c}\text { Cadernos CEDES/ } \\
\text { Scielo }\end{array}$ & $\begin{array}{l}\text { Observando estratégias e } \\
\text { buscando soluções: a resolução } \\
\text { de operações por adolescentes } \\
\text { surdos }\end{array}$ \\
\hline $\begin{array}{l}\text { Picoli } \\
\text { Giongo }\end{array}$ & 2010 & $\begin{array}{l}\text { Arvorezinha/RS - } \\
\text { Instituto Estatual de } \\
\text { Educação }\end{array}$ & $\begin{array}{c}\text { Dissertação } \\
\text { (Mestrado)/BDTD }\end{array}$ & $\begin{array}{l}\text { Alunos/as surdos/as e processos } \\
\text { educativos no âmbito da } \\
\text { educa ção matem átic a: } \\
\text { problematizando relações de } \\
\text { exclusão/inclusão }\end{array}$ \\
\hline $\begin{array}{l}\text { Roch a e } \\
\text { Kawasaki }\end{array}$ & 2014 & $\begin{array}{l}\text { Belo Horizonte/MG - } \\
\text { Escola Pública } \\
\text { Municipal }\end{array}$ & $\begin{array}{c}\text { Dissertação } \\
\text { (Mestrado)/BDTD }\end{array}$ & $\begin{array}{l}\text { Ensinando geometria espacial } \\
\text { para alunas surdas de uma escola } \\
\text { pública de Belo Horizonte (MG) }\end{array}$ \\
\hline Sales et al. & 2015 & $\begin{array}{l}\text { Rio Claro/SP- } \\
\text { Escola Pública } \\
\text { Municipal }\end{array}$ & $\begin{array}{c}\text { Ciência e } \\
\text { Educação/Scielo }\end{array}$ & $\begin{array}{l}\text { A Negociação de Sinais em Libras } \\
\text { como Possibilidade de Ensino e } \\
\text { de Aprendizagem de Geometria }\end{array}$ \\
\hline
\end{tabular}


Arnoldo Junior et al. (2013) investigaram em uma escola para surdos o uso do multiplano e o desenvolvimento do pensamento geométrico, onde o multiplano foi utilizado para a criação de sinais. A pesquisa ocorreu entre os anos de 2008 e 2010 e foi realizada com educandos do Ensino Fundamental de uma escola de surdos da cidade de Porto Alegre no Rio Grande do Sul, em que os educandos tinham idade entre 18 a 35 anos.

Os autores avaliaram que o estudo possibilitou observar que os classificadores de Libras não têm apenas função comunicativa, pois são indispensáveis para a formação e estruturação do pensamento. Sendo assim, as figuras, as fotos e outros recursos visuais estimulam o pensamento por sinais, permitindo que os educandos surdos compreendam melhor o pensamento geométrico, com certeza o estudo é emergente e mostra que é necessário a convenção de classificadores de Libras e a emancipação de sinais em educação matemática.

O multiplano, objeto de estudo dos autores Arnoldo Junior et al., é um recurso divertido, fácil, interativo e possibilita ao educador criar várias formas de ensinar matemática e estatística a seus educandos. É constituído por um tabuleiro retangular operacional no qual são encaixados pinos, fixados elásticos, hastes de corpo circular para sólidos geométricos, hastes para cálculo em funções ou trigonometria, base de operação, barras para gráficos de estatísti$\mathrm{ca}$, disco circular que apresenta em sua periferia uma sequência de orifícios circulares, onde podem ser combinadas duas ou mais peças pertinentes a uma determinada operação matemática que se pretenda aprender e compreender por meio da visão e ou do tato.

Em conformidade com Vales (2008, p.19) "a visualidade é o meio que os surdos dispõem para aprender e se relacionar com as coisas do mundo, visto que o meio de aquisição de informação obrigatoriamente passa pelo canal visual". Pertinente ao exposto, vem a afirmar o estudo de Arnoldo Junior et al., no qual os recursos visuais, como as imagens, estimulam a fixação do aprendiza- 
do, ainda mais quando se trata de matemática, em que tem-se muitos recursos como gráficos, figuras geométricas e entre tantos outros.

Barbosa (2014) avaliou os conceitos matemáticos iniciais e a linguagem, por meio de quantidade numérica, comparando crianças surdas e ouvintes. Foram avaliadas crianças de 5 a 6 anos, num universo de 14 crianças, de escolas particulares e públicas. Os resultados mostram que as crianças surdas e ouvintes apresentam o mesmo nível de representação numérica quando o estímulo é de natureza não linguística. Quanto às habilidades quantitativas simbólicas, o perfil se apresenta de forma mais complexa. As crianças surdas no geral, tiveram um desempenho inferior em relação às crianças ouvintes, com um ano aquém de idade ( 5 anos) das escolas infantis privadas, assim como também, em relação à criança da mesma idade (6 anos) das escolas públicas.

Justificando, assim, porque a criança surda na sua grande maioria, tem a preocupação de se comunicar com as pessoas, formando palavras por meio de sinais. E, por conseguinte, as habilidades quantitativas simbólicas, ficam num segundo plano.

Corrêa e Kopke (2013) em seu estudo trabalharam com educandos de 16 a 18 anos do Ensino Fundamental, $6^{\circ}$ ano e $7^{\circ}$ ano. Elas utilizaram imagens e desenhos para que os educandos com o apoio do recurso físico apresentado, tivessem uma base ilustrativa para desenvolver os cálculos. Assim, as autoras notaram nos cinco educandos da pesquisa que cada um deles tem um desenvolvimento diferente em relação ao raciocínio matemático. Também foi possível notar que o educando que possui um desenvolvimento mais apurado matematicamente é aquele educando que possuí na família outro indivíduo surdo. As autoras evidenciaram que os educandos surdos realizaram os cálculos mecanicamente sem ter nenhum significado para eles.

A grande maioria dos educandos surdos são filhos de pais ouvintes, e com isso os pais tentam de alguma forma levar esta criança a oralidade, a língua falada, buscando e aplicando várias técnicas de reabilitação da audição. Por tanto, ao analisar o estudo das autoras, o educando que apresentou um 
desenvolvimento matemático mais apurado é porque convive com outro sujeito surdo desde a nascença, desenvolvendo mutuamente e sem nenhuma influência externa esse raciocínio matemático.

O estudo de Fernandes e Healy (2016) verificou a emergência do pensamento algébrico nas atividades de educandos surdos, mostrando que há indicadores de que os educandos foram conduzidos a uma práxis reflexiva mediada pelo corpo, pelos signos e pelas ferramentas. A turma envolvida nas atividades de pesquisa era composta por seis educandos surdos, com idades que variavam entre 18 e 31 anos, matriculados no $9^{\circ}$ ano do Ensino Fundamental de uma escola do município de Barueri, São Paulo. Os autores afirmam que houve mudanças no pensamento algébrico de acordo com as interpretações e os sentidos subjetivos que os educandos foram atribuindo aos objetos matemáticos, principalmente quando foi introduzido micromundo MATHSTICKS permitindo, aos educandos, explorarem as estruturas visuais das sequências e encontrarem a possibilidade de gerar uma representação simbólica para um termo geral.

Para Radford (2008) apenas pensa-se algebricamente quando se identifica uma sequência e perante essa sequência cria-se uma regra ou esquema para representar esta sequência, conforme Figura 1. Segundo Conceição (2011) uma maneira de chegar à generalização algébrica, é perceber a regularidade de crescimento da sequência, $1^{\circ}$ termo $=1+1+1$ bolinhas, $2^{\circ}$ termo $=2$ $+2+1$ bolinhas, $3^{\circ}$ termo $=3+3+1$ bolinhas, e dessa forma afirmar que os próximos termos serão $n+n+1$ bolinhas, para qualquer posição da sequência.

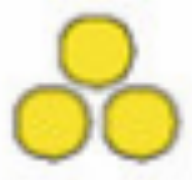

Fig. 1

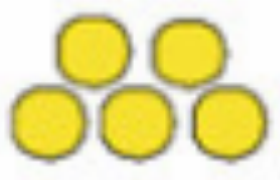

Fig. 2

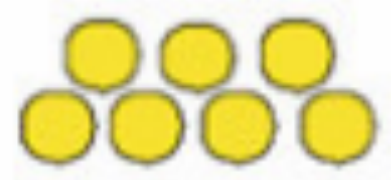

Fig. 3

Figura 1 - Sequência de círculos apresentadas por Radford Fonte: Radford (2008) 
Logo, o software micromundo MATHSTICKS, utilizado por Fernandes e Healy, trabalham com sequências, que podem vir a ajudar os educandos surdos no contexto matemático. É um software com interface simples e interativa, suas sequências são compostas por palitos e pontos, em que os educandos podem formar figuras e aprender álgebra, conforme figura 2.

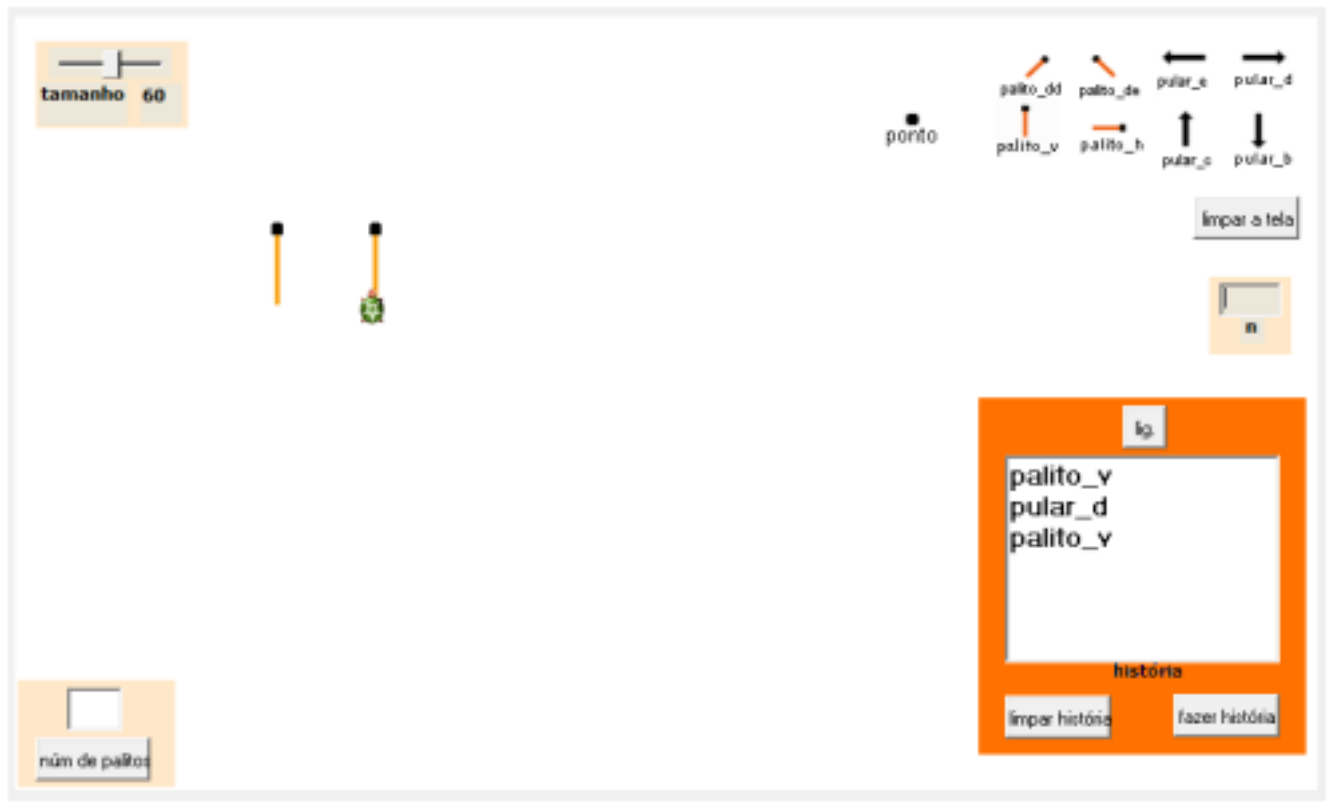

Figura 2 - Software micromundo MATHSTICKS

Fonte: http://www.micromundo.com.br/soft/photoonyx.php

As autoras Fernández-Viader e Fuentes (2013) observaram nas suas pesquisas estratégias e buscaram soluções, assim como a resolução de operações básicas como a adição e subtração, por adolescentes surdos, em uma escola em Barcelona na Espanha. Esta escola é considerada compartilhada, recebe educandos surdos e ouvintes, que estudam na mesma sala de aula. Elas analisaram que quanto proposto os exercícios de adição os educandos não apresentaram erros ao somar, porém quanto proposto exercícios de subtração, os educandos apresentaram muitos erros, com uma média acima do normal e do esperado.

Por conseguinte, as autoras afirmam que há um atraso muito grande em educandos surdos no que diz respeito a área da matemática, e que pode estar 
relacionado a falta de estrutura das escolas para receberem estes educandos surdos, ao despreparo dos educadores e por estes educandos fazerem parte de famílias ouvintes e não estarem familiarizados com os números.

O papel do educador é primordial para que aja o aprendizado, a conexão e a afetividade refletem na aprendizagem. Para que ocorra este aprendizado é necessário que o educador tenho o conhecimento de Libras, sendo assim, possível estabelecer diálogo com o seu educando.

Picoli e Giongo (2010) em seu estudo com educandos do Ensino Fundamental e Ensino Médio, com idades entre 16 e 18 anos, realizaram sua prática investigativa em três encontros com intervalo de uma semana para cada encontro. Utilizaram a calculadora como ferramenta para cálculos das operações básicas, como adição, subtração, multiplicação e divisão; propondo uma atividade de compras e vendas, montando um mercado fictício. As autoras neste trabalho, puderam analisar que os educandos surdos operaram com resultados matemáticos utilizando outra lógica e outro raciocínio diferentemente gestados na matemática escolar com educandos sem surdez. Para tanto, as autoras retratam que é necessário repensar no currículo e propiciar o uso adequado de Libras.

No Quadro 2 é apresentado o nível de ensino, a idade dos educandos investigados, a temática e o método utilizados nas pesquisas inclusas no artigo. 


\begin{tabular}{|c|c|c|c|c|}
\hline Autor IAno & Ensino & $\begin{array}{l}\text { Idade } \\
\text { (anos) }\end{array}$ & Temática & Método \\
\hline $\begin{array}{l}\text { Arnoldo Junior et al. } \\
\text { (2013) }\end{array}$ & Fundamenta & 18 a 35 & Geometria & Multiplano \\
\hline Barbosa (2014) & $\begin{array}{l}\text { Educação } \\
\text { Infantil }\end{array}$ & 5 a 6 & $\begin{array}{c}\text { Tarefas } \\
\text { experimentais }\end{array}$ & Quantidade numérica \\
\hline $\begin{array}{l}\text { Corrêa e Kopke } \\
\text { (2013) }\end{array}$ & $\begin{array}{l}\text { Fundamenta } \\
6^{\circ} \text { e } 7^{\circ} \text { ano }\end{array}$ & 16 a 18 & Divisão & Materiais de natureza visual \\
\hline $\begin{array}{l}\text { Fernandes e Healy } \\
(2016)\end{array}$ & $\begin{array}{c}\text { Fundamenta } \\
\text { I } \\
9^{\circ} \text { ano }\end{array}$ & 18 a 31 & LOGO & $\begin{array}{l}\text { Micromundo } \\
\text { MATHSTICKS }\end{array}$ \\
\hline $\begin{array}{l}\text { Fernández-Viader e } \\
\text { Fuentes (2013) }\end{array}$ & Fundamenta & 12 a 15 & $\begin{array}{l}\text { Resolução de } \\
\text { operações }\end{array}$ & Contas de subtração e adição \\
\hline Picoli e Giongo & $\begin{array}{c}\text { Fundamenta } \\
\text { l } \\
\left(7^{\circ} \text { ano }\right) \text { e } \\
\text { Médio } \\
\left(3^{\circ} \text { ano }\right)\end{array}$ & 16 a 18 & Operações Básicas & Calculadora \\
\hline $\begin{array}{l}\text { Rocha e Kawasaki } \\
\text { (2014) }\end{array}$ & $\begin{array}{c}\text { Fundamenta } \\
\text { I } \\
9^{\circ} \text { ano }\end{array}$ & 14 a 18 & $\begin{array}{l}\text { Geometria } \\
\text { Espacial }\end{array}$ & $\begin{array}{l}\text { Materiais manipulativos e } \\
\text { materiais de natureza visual }\end{array}$ \\
\hline $\begin{array}{l}\text { Sales et al. } \\
(2015)\end{array}$ & $\begin{array}{c}\text { Fundamenta } \\
\text { I } \\
5^{\circ} \text { ano }\end{array}$ & 10 a 13 & Geometria & $\begin{array}{l}\text { Sistema de notação em } \\
\text { palavras }\end{array}$ \\
\hline
\end{tabular}

Quadro 2 - Principais características dos artigos analisados na revisão sistemática Fonte: Dados da pesquisa, 2017

Rocha e Kawasaki (2014) procuraram entender como o uso de recursos didáticos, como os materiais manipulativos - utilizados por educandas surdas do $9^{\circ}$ ano do Ensino Fundamental de uma escola pública de Belo Horizonte, em aulas em que fossem estimuladas ao diálogo através de questionamentos favorecem a aprendizagem de Geometria Espacial quanto à ampliação do vocabulário em Língua de Sinais e o português escrito.

$\mathrm{Na}$ pesquisa das autoras, participaram quatro educandas surdas com idade entre quatorze e dezoito anos de uma turma exclusiva de alunas surdas. Nessa perspectiva, os materiais manipulativos foram pensados como ferramentas de mediação da aprendizagem e estavam disponíveis, durante todo o tempo para as alunas, conforme Figura 3. Assim, as autoras, verificaram no seu 
estudo possibilidades significativas para a aprendizagem das educandas, observando respostas satisfatórias em relação aos conceitos de Geometria Espacial, estabelecendo, negociando e compartilhando sinais em Libras de termos matemáticos, criados pelas educandas ao longo do processo.

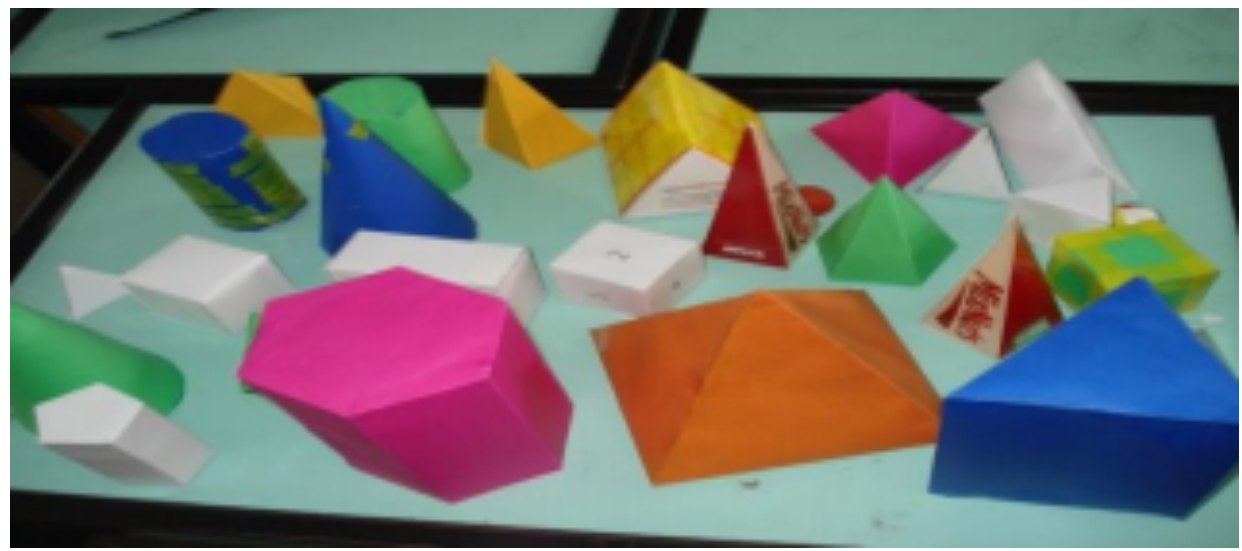

Figura 3 - Superfícies geométricas confeccionadas pelas autoras Fonte: Rocha e Kawasaki (2014)

Sales et al. (2015) no seu estudo analisaram a negociação de sinais em Libras como possibilidade de ensino e de aprendizagem de geometria. No entanto, os autores em sua pesquisa, notam a ausência de sinais específicos em Libras, para representar alguns elementos de geometria e a dificuldade que os educandos surdos têm em representar a geometria. No estudo eles trabalharam com doze educandos, 8 surdos e 4 ouvintes, com faixa etária entre 10 e 13 anos, notando que houve a interação entre o educador e o educando na tentativa de criar simbologias, para a representação geométrica, porém, ainda segundo os autores:

Algumas variáveis podem contribuir para as barreiras comunicativas em sala de aula como: a formação dos educadores, recursos da escola, acessibilidade, políticas de inclusão, fluência em Libras por parte dos pais, educandos e educadores, dentre outras (SALES et al., 2015, p.1283).

Pode-se observar, com base nos estudos encontrados, que existe uma preocupação maior em adaptar e ensinar matemática para educandos surdos 
na Educação Infantil, no Ensino Fundamental e no Ensino Médio, porém a grande maioria dos artigos, dissertações e teses são direcionadas para o Ensino Fundamental. Outro fato relevante é a faixa etária destes educandos do Ensino Fundamental, na grande parte dos estudos analisados, os autores frisaram que os educandos na sua maioria repetem de ano pelas dificuldades que enfrentam com a linguagem matemática, por não existir uma linguagem específica.

\section{CONSIDERAÇÕES FINAIS}

A sociedade vem ampliando gradativamente a importância da inclusão social, principalmente em ambientes escolares. Para isso a sociedade, a família e os educadores precisam estar preparados. É preciso que o educador busque a formação continuada, a adaptação e a diversificação de conteúdos que devem fazer parte de uma preparação para a aprendizagem que o educador levará aos seus educandos, a fim que os mesmos se sint0am satisfeitos e iguais a todos os outros educandos, sem exclusão e sem preconceito.

Para este estudo foram encontradas muitas dificuldades para a inclusão dos artigos que retratassem sobre a inclusão de educandos surdos no contexto escolar. Em relação à língua dos sinais como possibilidade de ensino de matemática foram maiores ainda as dificuldades. Vindo a mostrar que o assunto é de enorme relevância, visto que a matemática desperta no educando o interesse pela construção, o desenvolvimento do raciocínio lógico, tornando o indivíduo um ser crítico.

Em todos os estudos foram relatados que os educandos surdos conheciam a língua dos sinais, mais não conheciam nenhum símbolo matemático, expressão, figura geométrica e a construção de números, consequentemente, apresentaram dificuldades e déficit no raciocínio lógico.

Por fim, acredita-se que os cursos de Licenciatura em Matemática,00 assim como outros cursos de graduação, necessitam capacitar seus graduandos com condições que permitam a realização de uma educação inclusiva, evi- 
tando a exclusão e o fracasso escolar em relação aos educandos surdos. Formando um novo legado de profissionais responsáveis, acolhedores e que se permitam inovar e buscar toda e qualquer fonte de conhecimento que agregue qualidade na vida dos estudantes surdos.

Segundo Agapito et al. (2015), com as mudanças nas legislações em torno das Libras como disciplina de cursos superiores, exige que os graduandos tenham conhecimento da língua. Assim, o artigo $3^{\circ}$ do decreto no 5.626/05 diz que "A Libras deve ser inserida como disciplina curricular obrigatória nos cursos de formação de professores para o exercício do magistério, em nível médio e superior, e nos cursos de Fonoaudiologia, de instituições de ensino, públicas e privadas" (BRASIL, 2005).

Perante, Souza (2017, p.82), a inclusão de Libras no Ensino Superior é uma grande "conquista no que diz respeito à educação dos surdos, já que se supõe que o preparo adequado de educadores pode favorecer uma educação de qualidade aos educandos surdos em situação de inclusão".

Este estudo será ampliado para investigar outras pesquisas que foram realizadas em outros países, relacionando educação inclusiva com o ensino da matemática, assim como, dificuldade dos educandos surdos com a linguagem matemática e a língua dos sinais como possibilidade de ensino de matemática.

\section{REFERÊNCIAS}

AGAPITO, F. M. et al. Libras na área de ciências naturais: busca por articulação entre conhecimentos. Revista do Grupo de Pesquisa Educação, Artes e Inclusão (GPEAI/UDESC), v. 11, n. 2 (2015). DOI: http://dx.doi.org/ $\underline{10.5965 / 198431781122015008}$

ARNALDO JR. et al. O uso do multiplano por alunos surdos e o desenvolvimento do pensamento geométrico. Cad. Cedes, Campinas, v. 33, n. 91, p. 387-409, set.dez. 2013.

ARROYO, M. Outros Sujeitos, Outras Pedagogias. 2. Ed. Petrópolis, RJ: Vozes, 2014.

BARBOSA, $\mathrm{H}$. Conceitos matemáticos iniciais e linguagem: um estudo comparativo entre crianças surdas e ouvintes. Educação e Pesquisa 40(1):163-179 - March 2014. 
BRASIL. Decreto No 5.626. Regulamenta a Lei $n^{\circ} 10.436$, de 24 de abril de 2002, que dispõe sobre a Língua Brasileira de Sinais - Libras, e 0 art. 18 da Lei $\mathrm{n}^{\circ}$ 10.098, de 19 de dezembro de 2000. Publicada no Diário Oficial da União em 22/12/2005.

BRASIL. Relatório Nacional PISA 2012 - Resultados brasileiros. Disponível em: http://download.inep.gov.br/acoes internacionais/pisa/resultados/2014/relatorio nacional_pis a_2012_resultados_brasileiros.pdf. Acesso em: 01 de jul. de 2018.

CONCEIÇÃO, K. E. O micromundo MATHSTICKS: uma nova forma para interagir algebricamente com alunos surdos? III Seminário Internacional de Educação Matemática - SIEMAT III. Uniban, São Paulo, 2011.

CÔRREA, A. M.; KOPKE, R. C. A divisão por alunos surdos: ideias, representações e ferramentas matemáticas. Tese (doutorado) - Universidade Federal de Juiz de Fora, Instituto de Ciências Exatas, 2013.

COSTA, W. C., BARATA, R.C. Alfabetização Matemática e Educação de Surdos: alguns apontamentos. Educação Matemática na Contemporaneidade: desafios e possibilidades São Paulo - SP, 13 a 16 de julho de 2016.

FERNANDES, S.; HEALY L. A emergência do pensamento algébrico nas atividades de aprendizes surdos. Disponível em: http://www.scielo.br/pdf/ciedu/ v22n1/1516-7313-ciedu-22-01-0237.pdf Acesso em: 19 jan. 2018.

FERNÁNDEZ-VIADER, M.; FUENTES, M. Observando estratégias e buscando soluções: a resolução de operações por adolescentes surdos. Cad. Cedes, Campinas, v. 33, n. 91, p. 369-386, set.-dez. 2013.

INEP -. Instituto Nacional de Estudos e Pesquisas Educacionais. Anísio Teixeira. Ministério da Educação. Censo Educação 2015. Disponível em: < http://portal.inep.gov.br/boletim-de-desempenho> Acesso em: 01 de jul. 2018.

Kitchenham, B.; Charters, S. "Guidelines for performing systematic literature reviews in software engineering". Keele University and Durham University Joint Report, Tech. Rep. EBSE 2007-001, 2007.

LIMA, M. P.; CONCEIÇÃO, J. L. A importância da cultura e identidade surda na formação bilíngue no ensino regular. Encontro Internacional de Formação de Professores e Fórum Permanente de Inovação Educacional. v. 8, n. 1, p.332-342, 2015.

MACHADO, N. J. Matemática e Língua Materna. São Paulo: Cortez, 2011.

MIRANDA, C. J.; MIRANDA, T. L. O Ensino de Matemática para Alunos Surdos: Quais os Desafios que o Professor Enfrenta? Revemat: R. Eletr. de Edu. Matem. eISSN 1981-1322. Florianópolis, v. 06, n. 1, p.31-46, 2011. DOI: 10.5007/1981-1322.2011v6n1p31.

MIRANDA, W. Erros e obstáculos: os conteúdos matemáticos do ensino fundamental no processo de avaliação. 2007. Dissertação de Mestrado - Universidade Federal do Pará, Instituto de Educação Matemática e Científica, Programa de Pós-Graduação em Educação em Ciências e Matemáticas, Belém, 2007. 
PEREIRA, M. C. C. (org.). LIBRAS: conhecimento além dos sinais. São Paulo: Pearson Prentice Hall, 2011.

PICOLO, F. D.; GIONGO, I. M. Alunos/as surdos/as e processos educativos no âmbito da educação matemática: problematizando relações de exclusão/inclusão. 2010. Dissertação (Mestrado) - Curso de Ensino de Ciências Exatas, Centro Universitário UNIVATES, Lajeado, 25 jun. 2010. Disponível em: <http://hdl.handle.net/ 10737/118>.

QUADROS, R. M. de. 0 tradutor e intérprete de língua brasileira de sinais e língua portuguesa. Secretaria de Educação Especial. Brasília: MEC, SEESP, 2005.

Radford, L. (2008). Iconicity and Contraction: A Semiotic Investigation of Forms of Algebraic Generalizations of Patterns. ZDM - The International Journal on Mathematics Education.

ROCHA, F. B.; KAWASAKI, T. F. Ensinando geometria espacial para alunas surdas de uma escola pública de Belo Horizonte (MG): um estudo fundamentado na perspectiva histórico cultural 2014. Dissertação (Mestrado) - Universidade Federal de Ouro Preto. Instituto de Ciências Exatas e Biológicas. Departamento de Matemática.

SALES et al. A Negociação de Sinais em Libras como Possibilidade de Ensino e de Aprendizagem de Geometria. Disponivel em: http://dx.doi.org/ 10.1590/1980-4415v29n53a23 Acesso em: 19 jan. 2018.

SKLIAR, C. A surdez: um olhar sobre as diferenças. 5.ed. Porto Alegre: Mediação, 2011, p. 70.

SOUZA, R. de C. S. et al. Introdução aos estudos sobre educação dos surdos. Aracaju: Editora Criação, 2014.

SOUZA, J. M. R. DE; MARQUES, C. D. P.; SAMPAIO, M. L. P. Língua brasileira de sinais em contexto: inclusão dos indivíduos surdos. Revista do Grupo de Pesquisa Educação, Artes e Inclusão (GPEAI/UDESC), v. 9, n. 1 (2014). DOI: http://dx.doi.org/ $\underline{10.5960000000000000005 / 19843178912014}$

SOUZA, R. A. A implantação de Libras nas licenciaturas: desmistificando conceitos. Revista do Grupo de Pesquisa Educação, Artes e Inclusão (GPEAI/UDESC), v. 13, n. 3 (2017). DOI: http://dx.doi.org/10.5965/1984317813032017073

VALES, L.S. Pequeno dicionário regional de Libras para artes. Porto Alegre: UFRGS, 2008. Trabalho de conclusão de curso (Especialização em Pedagogia da Arte), Faculdade de Educação, Universidade Federal do Rio Grande do Sul, Porto Alegre, 2008. 